\title{
DISTRIBUIÇÃO ESPACIAL DE HUANGLONGBING (GREENING) EM CITROS UTILIZANDO A GEOESTATÍSTICA ${ }^{1}$
}

\author{
RENATA MOREIRA LEAL ${ }^{2}$, JOSÉ CARLOS BARBOSA ${ }^{3}$, MARILIA GREGOLIN COSTA ${ }^{4}$, \\ JOSÉ BELASQUE JUNIOR ${ }^{5}$, PEDRO TAKAO YAMAMOTO ${ }^{5}$, JOSÉ DRAGONE 6
}

RESUMO - Os objetivos do trabalho foram avaliar a distribuição espacial e a expansão da Huanglongbing (greening) em talhões de citros de uma propriedade agrícola localizada no município de Araraquara-SP, utilizando a geoestatística. Para determinar o número de plantas com greening, foram realizadas inspeções periódicas em intervalos de três meses, no período de março de 2005 a julho de 2007, contando-se, em cada talhão, o número de plantas com os sintomas característicos da doença. Realizou-se a análise descritiva dos dados e, para verificar a distribuição espacial do greening, utilizou-se a geoestatística através do ajuste de semivariogramas e da interpolação dos dados por krigagem. A dependência espacial de plantas com greening apresentou raio de agregação de 300 a 560 m, indicando distribuição agregada da doença. Por meio dos mapas de krigagem, observou-se que o foco inicial de plantas doentes ocorreu nos limites da fazenda, com expansão do greening por toda a área. O intervalo de inspeção de três meses não foi adequado para a redução do greening na fazenda.

Termos para indexação: Semivariograma, krigagem, Diaphorina citri.

\section{SPATIAL DISTRIBUITION OF HUANGLONGBING (GREENING) ON CITRUS USING GEOSTATISTIC}

\begin{abstract}
The aim of this study was to use geostatistics to verify the spatial distribution of Huanglongbing (greening) in oranges orchards on agricultural property located in the city of Araraquara, São Paulo. To determine the number of plants with greening, periodic inspections every three months were made from March 2005 until July 2007, counting the number of plants in each stand with the characteristic symptoms of the disease. A descriptive analysis of the data was undertaken, and geostatistics were used to verify the spatial distribution of greening through the adjustment of semivariograms and interpolation of data by kriging. The spatial dependence of plants with greening formed a beam of aggregation of 300 to $560 \mathrm{~m}$, indicated an aggregated distribution of the disease. Diagrams of kriging showed that initial focus of plants with greening started at the border in the farm and there was an expansion of the disease through the entire area. The interval of inspections every three months was not appropriate to reduce the greening in the farm.
\end{abstract} Index terms: Semivariogram, kriging, Diaphorina citri.

\section{INTRODUÇÃO}

O Brasil, impulsionado pelo crescimento das exportações, é atualmente o maior produtor mundial de laranjas, com cerca de 18 milhões de toneladas. Em 2007, o Estado de São Paulo foi responsável por $80 \%$ da produção nacional, obtida em área cultivada de 565 mil hectares, o que corresponde a uma área de $71 \%$ de toda produção citrícola brasileira (AGRIANUAL, 2008).
A cultura dos citros é uma das culturas que apresentam maior número de pragas e, dentre essas, atualmente, tem grande destaque o psilídeo Diaphorina citri Kuwayama (Hemiptera: Psyllidae). É um pequeno inseto que suga a seiva das plantas e tem causado, nos últimos anos, grandes prejuízos aos pomares cítricos, porque é o inseto vetor do procarioto causadoro greening.

O greening afeta todas as variedades cítricas e é considerada, atualmente, a doença de citros mais

'(Trabalho 059-09). Recebido em: 06-03-2009. Aceito para a publicação em: 08-04-2010. Parte da Tese de Doutorado da primeira autora.

${ }^{2}$ UNICASTELO, Faculdade de Agronomia. Estrada Projetada F1, s/nº Fazenda Santa Rita, 15600-000. Fernandópolis - SP. renatamleal@yahoo.com.br

${ }^{3}$ Prof. Dr. Depto. de Ciências Exatas FCAV/UNESP. jcbarbosa@fcav.unesp.br

${ }^{4}$ UNICASTELO, Faculdade de Ciências Agrárias. mariliagcosta@hotmail.com

${ }^{5}$ Pesquisador do Fundo de Defesa da Citricultura - FUNDECITRUS, C. P. 391, 18.801-970, Araraquara-SP. belasque@fundecitrus.com.br

${ }^{6}$ Departamento de Entomologia e Acarologia, ESALQ, USP. Avenida Pádua Dias, 11, 13418-900. Piracicaba - SP ptyamamoto@fundecitrus.com.br

${ }^{7}$ Engenheiro Agrônomo responsável pela fazenda Rancho Rey. 
importante no mundo, pois, de difícil controle, é altamente destrutiva para os pomares (BOVÉ, 2006). No Brasil, a doença foi identificada em julho de 2004, na região de Araraquara-SP (COLETA-FILHO et al., 2004) e, atualmente, está presente em vários municípios dos Estados de São Paulo, Minas Gerais e Paraná.

Entre os agentes causadores da doença, há a bactéria Gram-negativa, restrita ao floema da planta hospedeira, denominada Candidatus Liberibacter sp. Existem três espécies: Candidatus Liberibacter africanus, Candidatus Liberibacter asiaticus e Candidatus Liberibacter americanus, entretanto apenas $C$. Liberibacter asiaticus e $C$. Liberibacter americanus foram constatadas no Brasil (COLETA-FILHO et al., 2004).

Ainda, como agente causador da doença, há os fitoplasmas. Teixeira et al. (2008) avaliaram os sintomas característicos de greening em pomares de citros situados nas regiões norte, central e sul do Estado de São Paulo. Os autores verificaram, através de análises laboratoriais, que um fioplasma do grupo 16Sr IX esteve associado aos sintomas característicos de greening nos pomares de citros das regiões avaliadas.

O sintoma característico da doença ocorre, inicialmente, em um ramo, que se destaca por apresentar folhas de cor amarela, em contraste com o verde de ramos não afetados, provocando seca e morte dos ponteiros e redução no crescimento da planta; além disso, os frutos tornam-se pequenos, deformados e assimétricos (AYRES et al., 2005).

Em decorrência da importância dessa doença, alguns trabalhos foram desenvolvidos nos últimos anos, abordando principalmente medidas de controle do inseto vetor, porém estudos voltados à avaliação da dependência espacial do greening, nos pomares cítricos, são escassos.

Para estudar a dependência espacial, a geoestatística é a ferramenta mais adequada, pois considera a posição no espaço da variável em estudo (LIEBHOLD et al., 1993). Com o uso da geoestatística, é possível determinar a dependência espacial da doença, através da elaboração de semivariogramas que são ajustados a um modelo que fornece o raio de agregação de plantas doentes e, a partir desse semivariograma, é feita a elaboração de mapas que mostram como ocorre a expansão da doença na área.

Diante do exposto, os objetivos do trabalho foram avaliar a distribuição espacial e a expansão da Huanglongbing (greening) em talhões de citros de uma propriedade agrícola localizada no município de Araraquara-SP, utilizando a geoestatística.

\section{MATERIAL E MÉTODOS}

A pesquisa foi desenvolvida na fazenda Rancho Rey (Araraquara-SP), com os objetivos de estudar a dependência espacial e a expansão do greening em talhões de laranjeira [Citrus sinensis (L.) Osbeck]. A área experimental está compreendida entre as coordenadas geográficas $21^{\circ} 44^{\prime} 83^{\prime \prime}$ de latitude sul e $48^{\circ} 15^{\prime} 90^{\prime}$ " de longitude oeste de Greenwich e altitude de $647 \mathrm{~m}$ (parte central da fazenda). $\mathrm{O}$ experimento foi composto por 46 talhões de laranjeiras (Figura 1), com diferentes idades, espaçamentos, porta-enxertos (limoeiro Cravo e Cleópatra) e variedades (Hamlin, Murcott, Natal, Pera e Valência). O total de plantas na fazenda, no início do experimento, foi de 162.534 , e cada talhão possuía um determinado número de plantas que variou de 756 a 9.226. Os talhões receberam os tratos culturais (adubação, capina, aplicação de herbicidas) e fitossanitários (aplicação de acaricidas, inseticidas e fungicidas) recomendados à cultura. Para determinar o número de plantas com greening, foram realizadas inspeções periódicas em intervalos de aproximadamente três meses, no período de março de 2005 a julho de 2007, contando-se o número de plantas com sintomas característicos da doença em cada talhão. Quando se encontraram plantas com greening, essas foram eliminadas do talhão, seguindo a Instrução Normativa $\mathrm{N}^{\mathrm{o}} 10$ (Ministério da Agricultura, Pecuária e Abastecimento). As unidades amostrais do estudo foram compostas pelos talhões e, para o georreferenciamento dos mesmos, utilizou-se um GPS modelo Trimble 4600 LS, determinando-se as coordenadas geográficas do centro de cada talhão. Realizou-se a análise descritiva dos dados e, para verificar a dependência espacial e a expansão da doença, utilizou-se a geoestatística, através do ajuste de semivariogramas e da interpolação dos dados por krigagem (ROBERTO et al., 2002). A primeira etapa da geoestatística foi o ajuste do semivariograma que forneceu o tipo e a forma da dependência espacial, que nada mais é do que um gráfico da semivariância em função da distância. A semivariância é descrita como:

$\gamma(h)=\frac{1}{2 N(h)} \sum_{i=1}^{N(h)}\left[Z\left(x_{i}\right)-Z\left(x_{i}+h\right)\right]^{2}$ rr uma
em que, ${ }_{\text {distancia h; } N(h) \text { é o número de pares de observação }}^{2}$ ), separados pela distância h. A partir daí, foram ajustados aos dados os modelos de $\operatorname{se} Z\left(x_{i}\right)-\underline{Z}\left(x_{i}+h\right.$ isférico, exponencial, gaussiano ou potência. Neste estudo, o modelo de semivariograma 
que melhor se ajustou aos dados foi o gaussiano, que é descrito como: $\gamma(h)=C_{0}+C_{1}\left[1-\exp \left(-\frac{3 h^{2}}{a^{2}}\right)\right]$

em que, $C_{0}$ é o efeito pepita ou semivariância mínima; $C_{0}+C_{1}$ é o patamar ou semivariância máxima e, $a$ é o alcance ou raio de agregação. Em seguida, foi feita a construção dos mapas de krigagem que usam a dependência espacial modelada no semivariograma e estimam valores em qualquer posição do campo sem tendência e com variância mínima, permitindo visualizar o comportamento da variável em estudo por meio de mapas de isolinhas e de superfície. Para a análise dos dados, foram utilizados os programas estatísticos: MINITAB 14 (estatística descritiva) e o SURFER 7.0 (geoestatística).

\section{RESULTADOS E DISCUSSÃO}

Verificaram-se, na primeira inspeção, 426 plantas com greening, ou seja, $0,3 \%$ do total de plantas cultivadas na fazenda. Na segunda inspeção, houve um aumento do número de plantas doentes que correspondeu a 6.533 (4\%), sendo que, na fazenda, durante todo o período de inspeção, sempre existiram plantas com os sintomas da doença (Figura 2). Pode-se inferir que o intervalo de três meses entre uma inspeção e outra, no mesmo talhão, pode não ter sido adequado, pois plantas com greening, que ainda não apresentavam os sintomas da doença no momento da inspeção, permaneceram no campo por mais três meses, aumentando as fontes do inóculo nos talhões que foram responsáveis pela infecção daquelas plantas ainda sadias.

Observou-se grande variabilidade da área em estudo, pois quando se comparam os valores da média e da variância, verifica-se que os valores da variância sempre foram maiores que os da média (Tabela 1), indicando que as plantas doentes são encontradas na área de forma agregada. Ainda na mesma tabela, observam-se os altos valores do coeficiente de variação, o que, neste tipo de estudo, pode ser considerado normal, uma vez que foram realizadas comparações de plantas com greening entre talhões que apresentavam muitas plantas doentes e outros talhões que apresentavam poucas ou nenhuma planta com a doença.

$\mathrm{Na}$ análise geoestatística, as variáveis foram o número de plantas com greening presentes em cada um dos 46 talhões de citros. A dependência espacial do número de plantas de citros com greening foi estudada por meio de semivariogramas e o modelo que melhor se ajustou aos dados foi o gaussiano, apresentando o maior coeficiente de determinação
(Figura 3).

Foram elaborados os semivariogramas das plantas de citros com greening das oito inspeções (Figura 3), os quais apresentaram um alcance de dependência espacial de 450 a 560 m, com exceção da última inspeção, que foi de $300 \mathrm{~m}$ (Figura 3). O alcance de dependência espacial da última inspeção foi menor em relação às anteriores porque, no decorrer das inspeções, à medida que se encontravam plantas doentes nos talhões, estas foram eliminadas e, além disso, alguns talhões foram erradicados por completo da fazenda devido ao grande número de plantas doentes. O número de talhões utilizados na primeira inspeção foi de 46 , restando, na última inspeção, apenas 37 talhões.

O alcance de dependência espacial é de grande importância, pois além de indicar o raio de agregação das plantas de citros com greening na fazenda, permite-nos fazer uma análise do intervalo de tempo em que as inspeções, no mesmo talhão, deverão ser realizadas. Através do raio de agregação das plantas de citros com greening, fornecido pelos semivariogramas durante as oito inspeções, pode-se concluir que o intervalo de três meses entre uma inspeção e outra, no mesmo talhão, não foi adequado, pois no decorrer das inspeções não houve diminuição relevante ou acentuada do raio de agregação (Figura 3).

Outro índice importante obtido através do semivariograma é a relação $\mathrm{C}_{0} /\left(\mathrm{C}_{0}+\mathrm{C}_{1}\right)$, que indica a forma de distribuição da doença. Segundo Journel e Huijbregts (1978), os valores da relação $C_{0}$, $\left(\mathrm{C}_{0}+\mathrm{C}_{1}\right)$ abaixo de 0,8 indicam distribuição agregada da variável. No presente estudo, os valores obtidos nas oito inspeções variaram de 0,01 a 0,008 (Figura 3 ), indicando que as plantas com greening se distribuíram de forma agregada, ou seja, na forma de reboleiras na fazenda.

Algumas pesquisas que utilizaram a geoestatística para avaliar a dependência espacial e a expansão de outras doenças dos citros também foram desenvolvidas. Gottwald et al. (1996) avaliaram a distribuição espacial e a temporal da Tristeza dos Citros e verificaram distribuição agregada da doença e expansão das plantas doentes por toda a área. Roberto et al. (2002) estudaram a dependência espacial da Clorose Variegada dos Citros (CVC) e também verificaram distribuição agregada da doença no campo, com um alcance de dependência espacial das plantas doentes de $10 \mathrm{a} 14 \mathrm{~m}$. Os autores observaram, através dos mapas de krigagem, expansão da CVC na área e concluíram que o uso da geoestatística foi de extrema importância para verificar o comportamento da doença na fazenda.

A geoestatística também foi utilizada para 
estudar a dependência espacial de diversos patógenos causadores de doenças em outras culturas, como Fusarium oxysporum em tomateiro (REKAH et al., 1999), Phytophthora infestans em tomateiro e batateira (JAIME-GRACIA et al., 2001), Venturia inaequalis em macieira (CHAREST et al., 2002) e Colletotrichum spp. em feijoeiro e algodoeiro (ALVES et al., 2006). Em todos os estudos, foi possível constatar dependência espacial das plantas doentes com posterior expansão da doença que ocorreu praticamente por toda área.

Para melhor visualização da evolução do greening na fazenda, foram elaborados os mapas de krigagem. Verificou-se, na primeira inspeção, que o foco inicial de plantas doentes se originou nos talhões mais próximos dos limites da fazenda, formando posteriormente uma reboleira de plantas com greening com raio de agregação de $500 \mathrm{~m}$. Provavelmente, esse foco inicial surgiu por psilídeos contaminados vindos da fazenda vizinha à do estudo, a qual já apresentava plantas com greening (Figura 4).

Gottwald et al. (1989), por meio de inspeções periódicas, verificaram que a maior quantidade de plantas com greening foi encontrada nos limites do talhão, principalmente quando o talhão vizinho também apresentava maior incidência de plantas doentes.

Na segunda inspeção, o raio de agregação das plantas de citros doentes foi mantido (500 $\mathrm{m})$; entretanto, o número de plantas doentes nessa inspeção foi muito superior ( 0 a 1.500 plantas $)$ ao encontrado na primeira inspeção ( 0 a 240 plantas). Além disso, verificou-se o surgimento de outro foco de plantas com greening nos talhões acima da reboleira inicial da primeira inspeção (Figura 4).

Nas terceira, quarta, quinta e sexta inspeções, observou-se além do surgimento de novos focos de plantas com greening, a expansão da doença, que praticamente ocupou mais da metade da área da fazenda, formando novas reboleiras com raio de agregação de 500 a 560 m (Figura 4). Portanto, através desses resultados, conclui-se mais uma vez que o intervalo de três meses entre uma inspeção e outra, no mesmo talhão, não foi adequado, pois sempre existiu na área plantas com greening, cujo raio de agregação das plantas doentes praticamente não foi diminuído.

Já na sétima e oitava inspeções, verificou-se a expansão do greening por toda a fazenda, ou seja, o surgimento de novos focos de plantas com greening e posterior formação de reboleiras do lado oposto daquela em que surgiu a primeira reboleira na fazenda (Figura 4).

A rápida expansão da doença por toda a fazenda deve-se à presença do psilídeo nos pomares o ano todo, e, de acordo com Yamamoto et al. (2001), seu pico populacional ocorre na primavera/verão com queda no outono/inverno e, portanto, mesmo nos períodos em que a população do inseto foi baixa, este transmitiu a bactéria das plantas contaminadas para aquelas ainda sadias.

O intervalo entre uma inspeção e outra (três meses), no mesmo talhão, também está relacionado com a expansão da doença, uma vez que plantas com greening permaneceram por muito tempo no campo, servindo como fonte do inóculo para a contaminação das plantas ainda sadias.

TABELA 1 - Estatística descritiva das plantas com greening dos 46 talhões de citros, em cada inspeção, da Fazenda Rancho Rey (Araraquara-SP).

\begin{tabular}{ccccccc}
\hline Inspeções & Média* $^{\text {Mediana }}$ & Variância & $\begin{array}{c}\text { Coeficiente de } \\
\text { Variação }\end{array}$ & Assimetria & Curtose \\
\hline $1^{\text {a }}$ & 9,26 & 1 & 840,51 & 313,05 & 5,83 & 36,91 \\
$2^{\text {a }}$ & 142,0 & 30 & 57435,3 & 168,75 & 2,37 & 5,51 \\
$3^{\text {a }}$ & 104,7 & 47 & 57279,2 & 228,56 & 5,19 & 29,99 \\
$4^{\text {a }}$ & 124,0 & 81 & 22234,9 & 120,25 & 2,34 & 5,16 \\
$5^{\text {a }}$ & 106,1 & 54 & 25801,6 & 151,39 & 3,54 & 15,19 \\
$6^{\text {a }}$ & 53,7 & 14 & 18053,3 & 250,16 & 4,81 & 25,67 \\
$7^{\text {a }}$ & 106,7 & 74 & 8955,6 & 88,69 & 1,05 & 0,41 \\
$8^{\text {a }}$ & 85,8 & 59 & 5440,3 & 85,95 & 1,41 & 1,24 \\
\hline
\end{tabular}

* Média do número de plantas com greening dos 46 talhões de citros. 


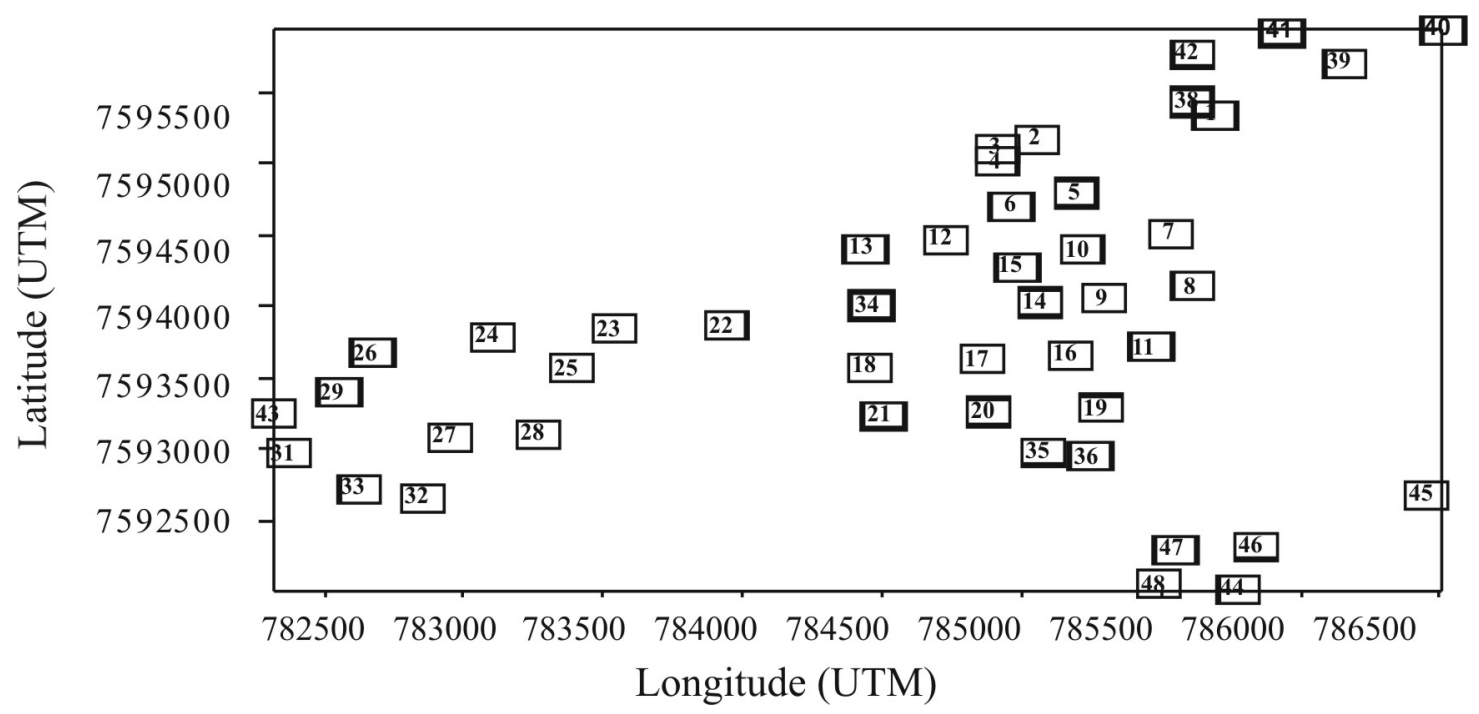

FIGURA 1 - Mapa de localização dos talhões de citros na Fazenda Rancho Rey (Araraquara-SP).

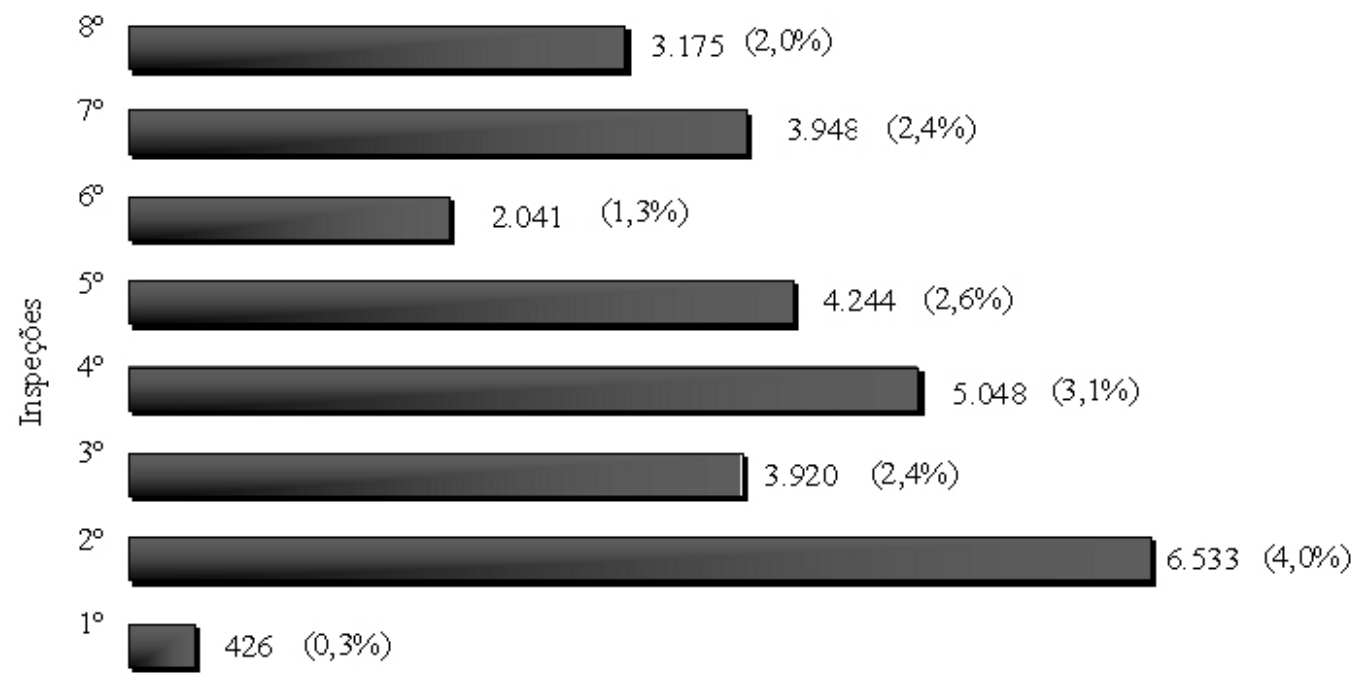

Quantidade de plantas de citros com greening na fazenda em cada insp eção

FIGURA 2 - Número total de plantas com greening dos 46 talhões de citros, em cada inspeção, da Fazenda Rancho Rey (Araraquara-SP). 

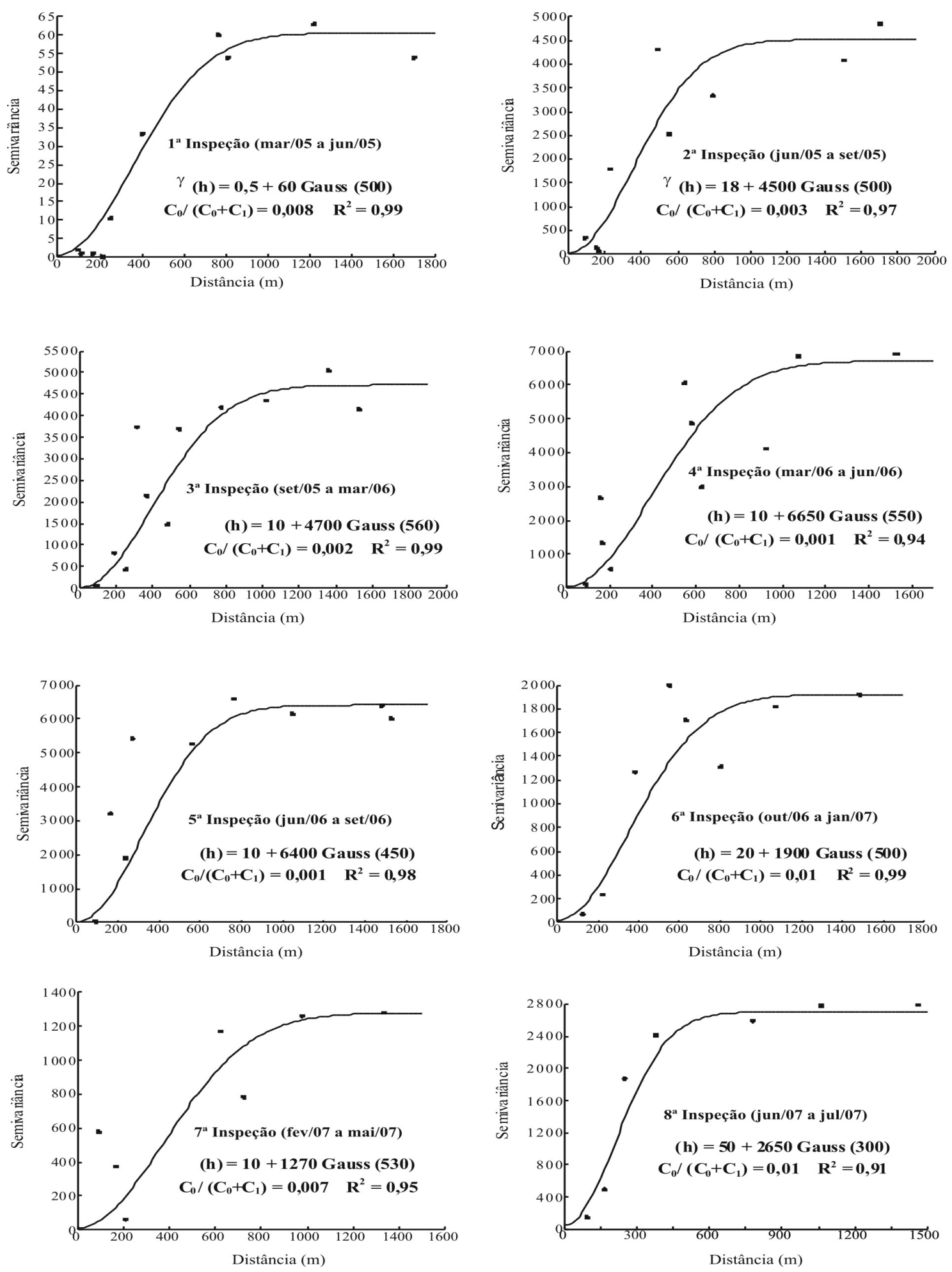

FIGURA 3 - Semivariograma das plantas com greening dos 46 talhões de citros, em cada inspeção, da Fazenda Rancho Rey (Araraquara-SP). 

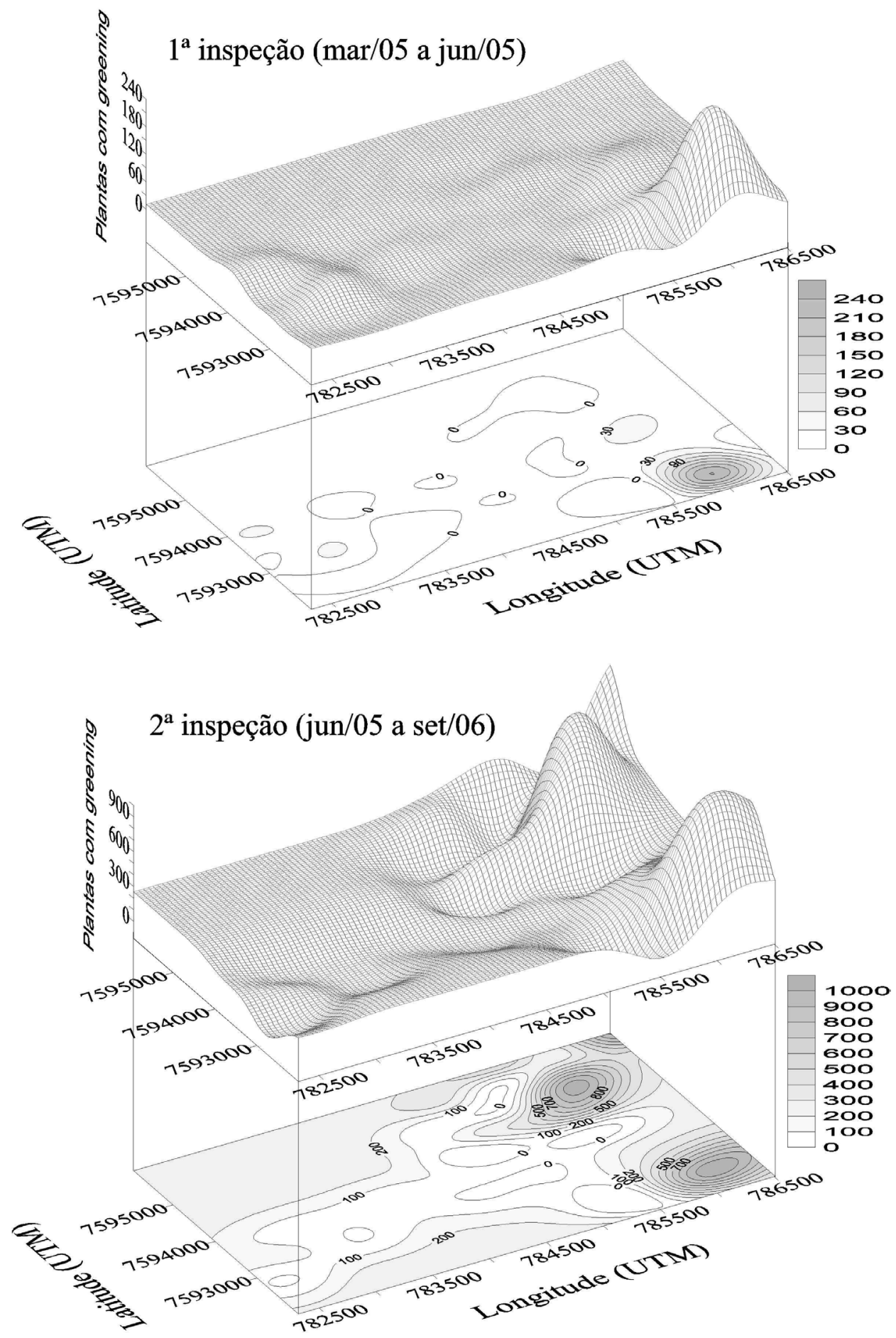

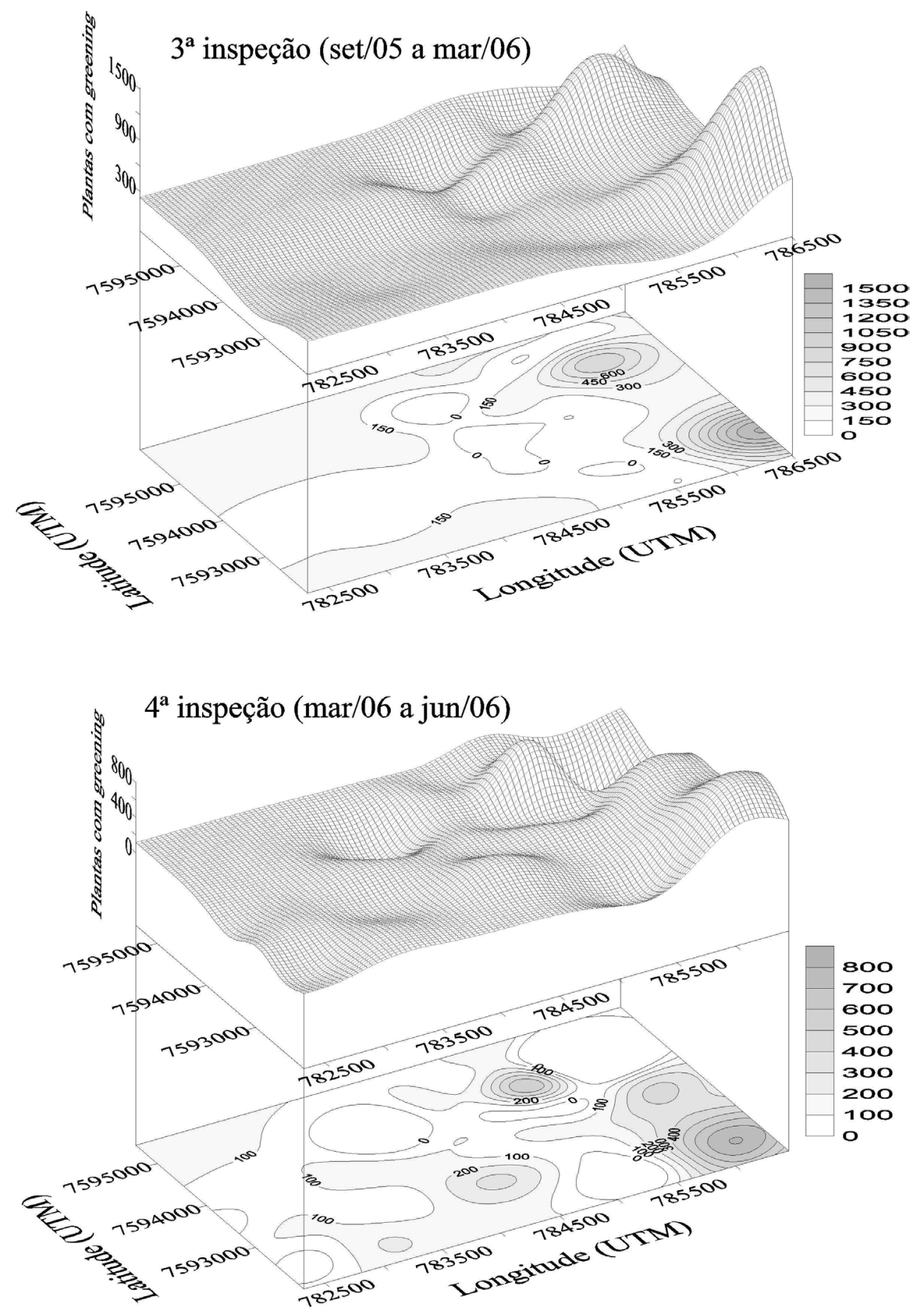

CONTINUA 

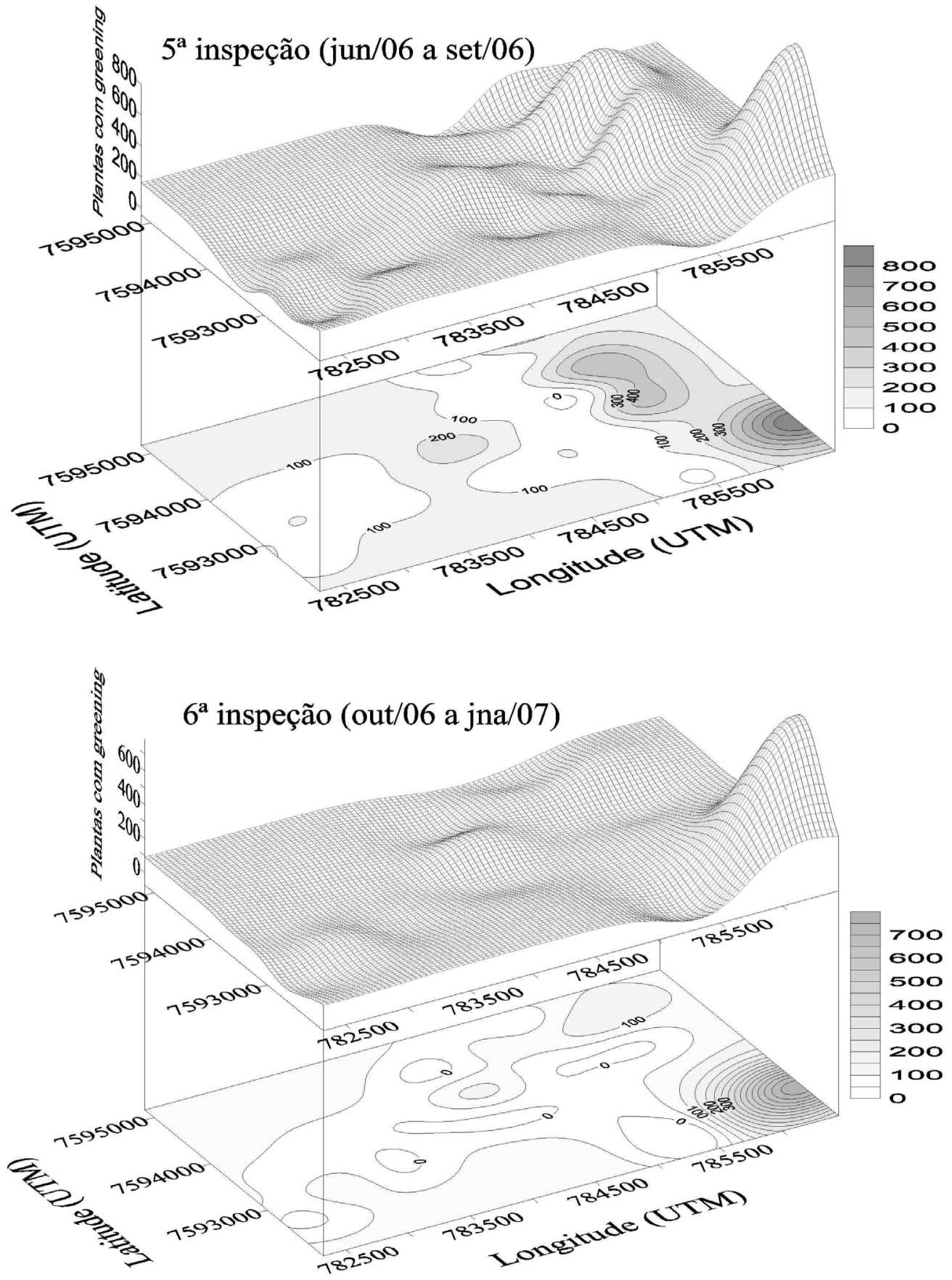

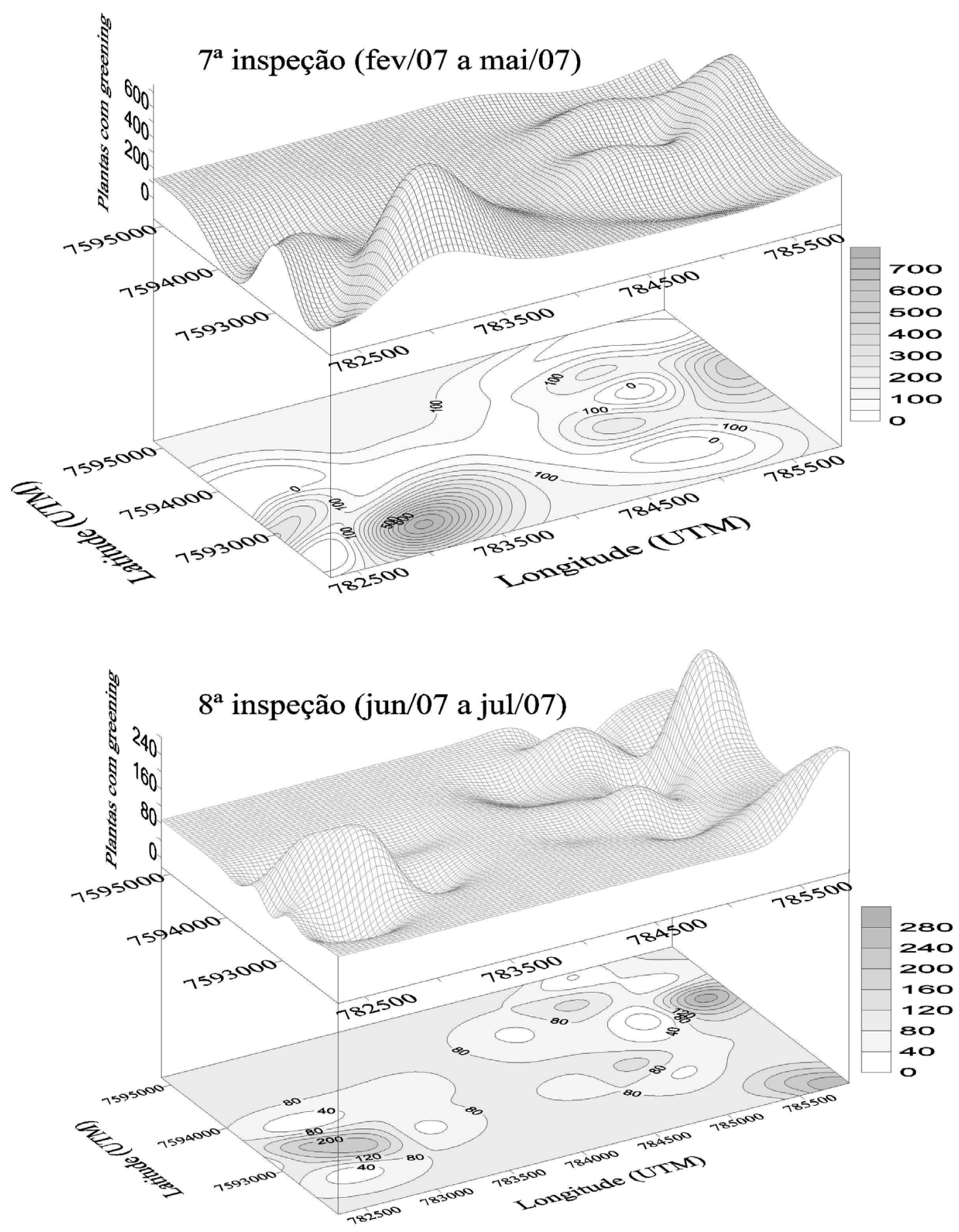

FIGURA 4 - Mapas de krigagem que mostram a expansão do greening por toda a fazenda de Citros durante o período das inspeções (05 de março a 07 de julho). 


\section{CONCLUSÕES}

1-A dependência espacial de plantas com greening apresenta raio de agregação de 300 a 560 $\mathrm{m}$, indicando distribuição agregada da doença.

2-Por meio dos mapas de krigagem, observase que o foco inicial de plantas doentes ocorre nos limites da fazenda com expansão do greening por toda a área.

3-O intervalo de inspeção de três meses não é adequado para a redução do greening na fazenda.

\section{REFERÊNCIAS}

AGRIANUAL 2007: anuário da agricultura brasileira. São Paulo: FNP Pesquisas, 2008. 520p .

ALVES, M.C.; POZZA, E.A.; MACHADO, J.C.; ARAÚJO, D.V.; TALAMINI, V.; OLIVEIRA, M.S. Geoestatística como metodologia para estudar a dinâmica espaço-temporal de doenças associadas a Colletotrichum spp. transmitidos por sementes. Fitopatologia Brasileira, Brasília, v.31, n.6, p. 557-563, 2006

AYRES, A.J.; BELASQUE, J.J.; SPÓSITO, M.B.; BASSANEZI, R.B.; LOPES, S.A. Manual de greening. Araraquara: Fundecitrus, 2005. 12 p.

BOVÉ, J.M. Huanglongbing: a destructive, newlyemerging, century-old disease of citrus. Journal Plant Pathology, Bari, v.88, n.1, p. 7-37, 2006.

CHAREST, J.; DEWDNEY, M.; PAULITZ, T.; PHILION, V.; CARISSE, O. Spatial distribution of Venturia inaequalis airborne ascospores in orchards. Phytopathology, Davis, v.92, n.7, p. 769-779, 2002.

COLETA-FILHO, H.D.; TAKITA, M.A.; TARGON, M.L.P.N.; CARLOS, F.E.; MACHADO, M.A. A bactéria Candidatus Liberibacter em plantas com Huanglongbing (ex-grenning) no Estado de São Paulo. Laranja, Cordeirópolis, v.25, n.2, p.367374, 2004

GOTTWALD, T.R.; AUBERT, B.; ZHAO, X.Z. Preliminary analysis of citrus greening (Huanglongbing) of China and French Reunion Island. Phytopathology, Davis, v.79, n. 6, p. 687-693, 1989.
GOTTWALD, T.R.; CAMBRA, M.; MORENO, P.; CAMARASA, E.; PIQUER, J. Spatial and temporal analyses of citrus tristeza virus in Eastern Spain. Phytopathology, Davis, v.86, n. 1, p. 45-55, 1996.

JAIME-GARCIA, R.; ORUM, T.V.; FELIX-GASTELUM, R.; TRINIDAD-CORREA, R.; VANETTEN, H.D.; NELSON, M.R. Spatial analysis of Phytophthora infestans genotypes and late blight severity on tomato and potato in the Del Fuerte Valley using geostatistics and geographic information systems. Phytopathology, Davis, v.91, n. 12, p. 1156-1165, 2001.

JOURNEL, A.G.; HUIJBREBTS, C.J. Mining geostatistics. London: Academic Press, 1978.

LIEBHOLD, A.M.; ROSSI, R.E.; KEMP, W.P. Geostatistic and geographic information system in applied insect ecology. Annual Review of Entomology, Palo Alto, v.38, n.1, p.303-327, 1993.

REKAH, Y.; SHTIENBERG, D.; KATAN, J. Spatial distribution and temporal development of Fusarium crown and root rot of tomato and pathogen dissemination in field soil. Phytopathology, Davis, v.89, n. 9, p. 831-839, 1999

ROBERTO, S.R.; FARIAS, P.R.S.; BERGAMIM FILHO, A. Geoestatistical analysis of spatial dynamics of citrus variegated chlorolis. Fitopatologia Brasileira, Brasília, v. 27, n.6, n. 6, p. 599-604, 2002.

TEIXEIRA, D.C.; WULFF, N.A.; MARTINS, E.C.; KITAJIMA, E.W.; BASSANEZI, R.; AYRES, A.J.; EVEILLARD, S.; SAILLARD, C.; BOVÉ, J.M. A phytoplasma closely related to the pigeon pea witches'-broom phytoplasma (16Sr IX) is associated with citrus huanglongbing symptoms in the State of São Paulo, Brazil. Phytopathology, Davis, v.98, n. 9, p. 977-984, 2008.

YAMAMOTO, P.T.; PAIVA, P.E.B.; GRAVENA, S. Flutuação populacional de Diaphorina citri Kuwayama (Hemiptera: Psyllidae) em pomares de citros na região norte do estado de São Paulo. Neotropical Entomology, Londrina, v. 30, n. 1, p. 165-170, 2001. 